\title{
A comunicação emocional na performance pianística
}

\author{
Danilo Ramos* \\ (Université de Bourgogne) \\ Rafael dos Santos \\ (Instituto de Artes da UNICAMP)
}

\section{Resumo}

Neste trabalho é apresentada uma abordagem psicológica do estudo da comunicação emocional em performance pianística. Neste sentido, o texto trará um pequeno histórico sobre o estudo das emoções musicais na cultura ocidental, bem como uma proposta para estudos sobre a comunicação emocional, procurando analisar, de forma integrada, o código acústico empregado pelo intérprete e a percepção emocional do ouvinte. Finalmente é apresentado no texto um modelo científico que procura investigar como se dá a acurácia no processo de comunicação emocional intérprete / ouvinte e sua possível aplicação na música instrumental brasileira. A conclusão deste trabalho é a de que o estudo da comunicação emocional em performance pianística traz contribuições importantes para áreas como Educação Musical e Percepção Musical.

Palavras-chave: emoções musicais; comunicação emocional; performance pianística; música instrumental brasileira.

\footnotetext{
* Danilo Ramos é graduado em Música Popular (modalidade: Piano) pela UNICAMP. É Mestre e Doutor em Psicologia pela USP, sendo orientado pelo Professor José Lino Bueno. Realizou seu pós-doutorado na Université de Bourgogne em Dijon, França, sob orientação do Professor Emmanuel Bigand. Atualmente, é professor aprovado no Departamento de Artes da Universidade Federal do Paraná, onde atua como professor desde 2011. Realiza pesquisas na área de Cognição Musical, sobretudo em estudos sobre as Emoções Musicais no repertório instrumental brasileiro. Atua regularmente como solista, compositor e professor.
}

Rafael dos Santos é Doutor em Música (modalidade: Piano) pela Universidade de lowa - EUA, sob a orientação do Prof. Daniel Shapiro. É Professor do Departamento de Música, Instituto de Artes da UNICAMP, onde participou da criação do curso de Música Popular. Coordena o Grupo de Pesquisa "Musica Popular: História, Produção e Linguagem" (CNPq). Atua regularmente como solista, arranjador, maestro, compositor e professor, além de ser coordenador do projeto de criação e implantação do Conservatório de Música Popular Cidade de Itajaí. 


\section{As emoções musicais}

Questões sobre música e emoção têm despertado o interesse dos seres humanos desde a antiguidade. Os gregos antigos já afirmavam que características específicas da música podiam ser associadas a algumas emoções (Juslin; Persson, 2001). Esta noção recebeu uma formulação mais precisa na Doutrina dos afetos durante os séculos XVII e XVIII (ver maiores detalhes em Metthenson, 1739; 1954). A partir de então, o conceito de "emoção musical" mudou muito no decorrer da história, tendo sido, no século XVIII, associado a uma espécie de "estado emocional racionalizado", em contraponto com o conceito de "expressão espontânea e pessoal" dos séculos XVII e XIX (ver maiores detalhes em Cook, 1998). As teorias modernas sobre as emoções musicais incluem as de Languer (1942), Meyer (1956), Cook (1959) e Clynes (1977). A pesquisa empírica sobre a expressão das emoções em música tem sido conduzida durante um século, incluindo os primeiro estudos de Hevner (1936), cujo trabalho explorou a propriedades expressivas de parâmetros musicais como altura, modo, timbre, entre outros. A partir de então, foi possível definir aspectos da composição musical que podem influenciar a expressão das emoções; no entanto, como estes aspectos se correlacionam é ainda um mistério.

Poucos estudos têm investigado como os músicos conceituam e atribuem um significado específico a uma peça musical durante o seu processo de preparação. Porém, tanto a pesquisa empírica (ver em Persson, 1993; Woody, 2000) quanto a pesquisa biográfica (ver em Blum, 1977; Menuhin, 1996; Schumacher, 1995) confirmam que musicistas sempre conceituam as suas performances musicais em termos de emoções e estados de humor. Além disso, muitos deles consideram a expressividade como o aspecto mais importante da performance musical (Boyd; George-Warren, 1992).

Em seu tratado sobre a verdadeira arte de executar instrumentos de teclas, Carl Phillipe Emmanuel Bach argumenta que "um músico não é capaz de comover as outras pessoas, se ele mesmo não estiver comovido [...] Para 
transmitir a sua idéia musical, ele sente a necessidade de vivenciar o tipo de afeto que acredita ser capaz de aumentar o nível de comoção em seus ouvintes" (1985, p. 152). A famosa cantora Janet Backer, em uma entrevista publicada em The observer, também conclui que "o negócio dos musicistas é trabalhar com a emoção e a sensibilidade, qualificando-os como "transmissores das sensações humanas" (publicado em Crofton; Fraser, 1985).

A maioria dos pesquisadores concorda que o termo "emoção musical" envolve um conjunto de fatores: (1) avaliação cognitiva: "você avalia uma música como sendo triste"; (2) sentimento subjetivo: "esta música me causa tristeza"; (3) aspectos fisiológicos: "você sente um arrepio quando ouve determinada música"; (4) expressão emocional: "você chora durante a escuta musical"; (5) tendência de ação: "você fica com vontade de desligar o rádio durante a escuta de uma determinada música" (Oatley; Jenkins, 1996). Além destes componentes, a literatura aponta duas principais abordagens acerca do conceito das emoções musicais: uma abordagem categórica, em que as pessoas classificam as emoções musicais como categorias que são distintas entre si (Ekman, 1992) e uma abordagem dimensional, que foca uma identificação de emoções musicais baseada no deslocamento das emoções em um espaço formado pela dimensão valência afetiva, que está relacionada à agradabilidade musical (podendo ser positiva ou negativa) e pela dimensão arousal, que está relacionada ao estado de excitação fisiológica do indivíduo (que pode ser alto ou baixo) durante uma escuta musical.

Considerando a abordagem dimensional, é possível mensurar as emoções com o auxílio de um referencial cartesiano, considerando o eixo das abcissas como sendo o eixo da valência afetiva e o eixo das coordenadas como sendo o eixo arousal. Assim, segundo o Modelo Circumplexo (Russel; 1980), as emoções musicais podem ser classificadas em quatro categorias: (1) "emoções que representam valência e arousal positivos", como a Alegria (por exemplo, quando se está alegre, sentimos uma emoção "positiva” e, ao mesmo tempo, um alto estado de excitação fisiológica; (2) "emoções que representam valência positiva e arousal negativo", como a Serenidade (quando se está sereno, sentimos uma 
emoção "positiva” e, ao mesmo tempo, um baixo estado de excitação fisiológica); (3) "emoções que representam valência negativa e arousal positivo, como a Raiva (quando se está raivoso, sentimos uma emoção "negativa” e, ao mesmo tempo, um alto estado de excitação fisiológica) e, finalmente, (4) "emoções que representam valência e arousal negativos", como a Tristeza (quando se está triste, sentimos uma emoção "negativa” e, ao mesmo tempo, um baixo estado de excitação fisiológica).

Um fator importante a ser levado em conta no uso deste modelo no estudo da avaliação emocional de eventos musicais é que nem sempre, em música, a emoção Tristeza pode ser entendida como tendo a propriedade de valência afetiva negativa. Segundo alguns dados encontrados por Ramos, Bueno e Bigand (no prelo), músicas consideradas como tristes foram percebidas como sendo agradáveis pelos ouvintes. Além disso, alguns participantes envolvidos no estudo também revelaram que as músicas em questão desencadeavam uma espécie de "tristeza artificial”, em que um simples “click" de um botão (no caso, o botão off do rádio) era o suficiente para que esta emoção "desaparecesse". Portanto, torna-se importante, para estudos futuros, que outras emoções sejam empregadas para representar o quadrante Tristeza do modelo de Russel em estudos sobre avaliação emocional em música, como, por exemplo, emoções mais profundas, que remetam a um imaginário "dolorido" da vida de uma pessoa, como por exemplo, temas de filmes cuja cena expressaria uma atmosfera de Agonia, Depressão, Desprazer, Melancolia, entre outras.

Existem, na literatura científica, diferentes procedimentos empregados para se mensurar as emoções musicais. Os principais são:

- medidas comportamentais: consistem na análise sistemática das manifestações comportamentais que o indivíduo pode expressar no decorrer de sua performance ou escuta musical e que podem ser mensuradas por meio da exteriorização de padrões comportamentais (expressões faciais, manifestações ritmo-corporais, exteriorizações de estados de ânimo como a distração, o sono etc.);

\footnotetext{
Ver maiores detalhes no modelo circumplexo de Russel, em Russel (1980).
} 
- medidas cognitivas - consistem na análise sistemática dos relatos verbais fornecidos pelos indivíduos durante ou após as performances ou escutas musicais, geralmente mensurados por meio de diferentes testes de avaliação emocional, como os de escolha forçada (em que o sujeito escolhe uma categoria emocional contida em uma pequena lista de emoções), testes envolvendo listas de adjetivos (em que o indivíduo escolhe um número adequado de adjetivos para identificar as emoções presentes em um evento musical), testes envolvendo taxas emocionais (em que o sujeito preenche uma escala de intensidade, com, geralmente, no mínimo 3 e no máximo 11 caselas, cuja tarefa é de quantificar a emoção presente no evento musical) e, finalmente, testes envolvendo descrições livres (em que o indivíduo descreve o evento musical utilizando as palavras que vierem à sua mente, cujos dados podem ser registrados oralmente de forma escrita).

- medidas psicofisiológicas: consistem na análise sistemática das alterações fisiológicas do indivíduo, por meio do uso de tecnologia apropriada; a maioria dos estudos utilizando estas medidas tem procurado mensurar o batimento cardíaco, a resposta galvânica da pele ou mesmo as imagens cerebrais do sujeito, com o auxílio do eletroencefalograma, durante ou após uma performance ou escuta musical.

\section{A comunicação das emoções em música: do código acústico empregado pelo intérprete à percepção emocional do ouvinte}

Juslin e Persson (2001) classificam o termo "comunicação emocional" àquelas situações em que o músico tem a intenção de comunicar emoções específicas aos ouvintes. Assim, a acurácia da comunicação musical existe quando a emoção intencionada pelo intérprete é entendida pelo ouvinte. Esta abordagem implica que a expressão e o reconhecimento de emoções devem ser estudados de forma integrada. A maioria dos estudos neste domínio tem usado o seguinte procedimento: (1) o músico é convidado a executar uma peça musical que expresse uma emoção 
específica (alegria, por exemplo), escolhida pelo pesquisador; (2) as performances são gravadas e depois analisadas de acordo com as suas características acústicas; (3) em seguida, as mesmas performances são julgadas por ouvintes, no intuito de verificar se as emoções intencionadas pelos músicos são as mesmas emoções percebidas pelos ouvintes. Sob este paradigma, vários estudos comprovaram que músicos profissionais são capazes de comunicar emoções aos ouvintes, apesar de terem sido detectadas diferenças individuais na habilidade expressiva (Kotlyar; Morozov, 1976; Behrens; Green, 1993; Gabrielsson; Juslin, 1996; Juslin, 1997b; Juslin, 2000; Juslin; Madison, 1999; Sundberg; Iwarsson; Hagegård, 1995).

Alguns estudos foram feitos nas últimas décadas com o objetivo de descrever o código (pistas acústicas) que os músicos usam para comunicar emoções específicas entre os ouvintes (Gabrielsson; Juslin, 1996; Juslin, 1997b; Juslin, 2000; Juslin; Madison, 1999; Juslin; Sloboda, 2001; Rapoport, 1996). Os resultados destes estudos mostraram que a expressão das emoções na performance musical envolve uma ordem considerável de pistas (pedaços de informação) que são usadas por músicos no processo de comunicação emocional. A Tabela 1 ilustra os principais resultados obtidos por estes estudos, em uma revisão feita por Juslin (2001) (Ver Tabela 1).

Um dado importante a ser considerado é o de que, em um estudo feito por Sloboda (1996) sobre a comunicação emocional em performance pianística, foi constatado que geralmente os instrumentistas estão inconscientes sobre os detalhes à respeito de como as suas intenções musicais são assimiladas pelos seus ouvintes. 


\section{Tabela 1}

Principais resultados obtidos em estudos que relacionam as emoções musicais com as pistas acústicas usadas por músicos no processo de comunicação emocional na revisão de Juslin (2001):

\begin{tabular}{|c|c|c|c|}
\hline Emoção & Pistas acústicas utilizadas pelos músicos & Arousal & Valência \\
\hline Alegria & $\begin{array}{l}\text { Andamento rápido e com pouca variabilidade, uso de } \\
\text { staccato, grande variabilidade de articulação, alto } \\
\text { volume sonoro, timbre brilhante, rápido ataque das } \\
\text { notas, pouca variação temporal, crescimento dos } \\
\text { contrastes de duração entre notas curtas e longas, uso } \\
\text { de microintonação para o agudo, pequena extensão de } \\
\text { vibrato }\end{array}$ & Alto & Positiva \\
\hline Tristeza & $\begin{array}{l}\text { Andamento muito lento, uso excessivo do legato, pouca } \\
\text { variabilidade de articulação, baixo volume sonoro, } \\
\text { contrastes reduzidos entre as durações das notas curtas } \\
\text { e longas, ataques lentos entre as notas, microintonação } \\
\text { para o grave, final ritardando e frases decelerando }\end{array}$ & Baixo & Negativa \\
\hline Raiva & $\begin{array}{l}\text { Alto volume sonoro, timbre agudo, ruídos espectrais, } \\
\text { andamento rápido, uso do staccato, ataques tonais } \\
\text { abruptos, crescimento dos contrastes de duração entre } \\
\text { notas curtas e longas, ausência do ritardando, acentos } \\
\text { súbitos, acentos sobre notas harmonicamente instáveis, } \\
\text { crescendo, uso de frases em accelerando, grande } \\
\text { extensão de vibrato }\end{array}$ & Alto & Negativa \\
\hline Amor & $\begin{array}{l}\text { Andamento lento, ataques lentos, baixo volume } \\
\text { sonoro, com pequenas variações, uso do legato, timbre } \\
\text { leve, moderadas variações do “timing musical”, uso } \\
\text { intenso do vibrato, contrastes reduzidos entre as } \\
\text { durações das notas curtas e longas, final ritardando, } \\
\text { acentos em notas harmonicamente estáveis }\end{array}$ & Baixo & Positiva \\
\hline Medo & $\begin{array}{l}\text { Uso do staccato, volume sonoro muito baixo, com } \\
\text { muita variabilidade, andamento rápido, com grande } \\
\text { variabilidade, grandes variações do “timing musical”, } \\
\text { espectro brilhante, rápido, superficial, vibrato irregular, } \\
\text { uso de pausas entre as frases e de sincopas súbitas }\end{array}$ & Moderado & Negativa \\
\hline
\end{tabular}

Persson (1993) realizou um estudo com o objetivo de verificar os aspectos emocionais envolvidos no significado atribuído à performance musical de 15 pianistas. Para isso, utilizou o Prelude, Op. 31, n. 1, de Reinhold Glière, desconhecido por todos os seus participantes. O procedimento envolvia a retirada de todas as pistas relativas à interpretação musical (dinâmicas, andamento, ornamentos etc.) fornecidas pelo compositor na partitura da obra. A tarefa dos pianistas consistia de, após estudarem o prelúdio por duas semanas, executá-lo, 
gravá-lo e discuti-lo com o pesquisador. Antes, porém, foi-lhes dito para lidar com a interpretação da peça da forma como eles acreditavam senti-la, ao invés de considerar as convenções convencionais relacionadas à interpretação de qualquer estilo musical. Além disso, os participantes deveriam atribuir um título ao prelúdio, que serviria de base para o início da discussão com o pesquisador. Os resultados mostraram que os participantes foram capazes de interpretar a obra sem o fornecimento das pistas convencionais relacionadas à interpretação musical. Os dados revelaram títulos das obras escolhidos conforme quatro critérios classificatórios: critério de aparência, referentes à associações extramusicais, como uma imagem (Lazy Sunday by the river, por exemplo); critérios de estado de humor, referentes à associações de significado emocional (Melancholy, por exemplo); critérios de idioma, referentes à associações que permitiram a identificação de algum estilo musical (Song without words, por exemplo) e, finalmente, critérios estruturais, referentes à associações musicais à idiomas de linguagem não musicais (I wonder why? Warum? Pourquoi? Pourquoi?, por exemplo). Concluiu-se, com este estudo, que é de extrema importância e utilidade compreender sobre os processos emocionais, sentimentais e afetivos envolvidos na expressão musical, pois são eles que permitirão que musicistas comuniquem e entendam “suas próprias músicas”.

Em outro estudo realizado por Ramos, Bueno e Bigand (no prelo), comprovou-se que duas pistas acústicas são suficientes para a obtenção de um processo robusto de comunicação das emoções musicais: o modo e o andamento. Assim, 7 trechos musicais oriundos do repertório folclórico brasileiro e executados ao piano por um dos pesquisadores foram transpostos para 7 modos (Jônio, Dórico, Frígio, Lídio, Mixolídio, Eólio e Lócrio) e para 3 andamentos (largo, moderato e presto) e depois apresentados a participantes não músicos, cuja tarefa era a de classificar cada trecho de acordo com as emoções que eles sentiam no momento da escuta, por meio de escalas de diferencial semântico, referente às emoções Alegria, Tristeza, Serenidade e Raiva. No intuito de verificar a influência da "aculturação musical” (definida como grau de familiaridade de um indivíduo a 
um determinado evento musical) sobre as respostas emocionais dos participantes, este estudo foi desenvolvido com participantes de dois grupos: brasileiros e franceses. De uma maneira geral, os resultados foram semelhantes entre os grupos: trechos musicais em andamentos rápidos e modos maiores foram associados à Alegria; andamentos lentos em modos menores foram associados à Tristeza; andamentos moderados em modos maiores foram associados à Serenidade; andamentos rápidos em modos menores foram associados ao Medo e à Raiva. Os resultados deste estudo levantaram a hipótese sobre um ponto essencial para a compreensão dos processos cognitivos envolvidos durante a escuta de música instrumental tonal: as emoções musicais parecem ser resultantes de processos cognitivos específicos, ou seja, dependem da cognição dos elementos da estrutura musical de uma obra. Assim, com relação à música instrumental executada em culturas ocidentais (e, portanto, tonais), estas descobertas recentes negaram a hipótese de que a música evoque emoções de acordo com a história pessoal de cada um.

\section{O Brunswikian Lens Model}

O Brunswikian lens model, adaptado por Juslin (1997b) é um modelo científico desenvolvido especificamente para tentar explicar os processos mentais envolvidos na comunicação das emoções musicais. Este modelo foi elaborado a partir de uma estrutura conceitual que considera dois parâmetros: (1) o natural, baseado em evidências acerca da existência de um programa cerebral inato para a expressão das emoções, considerando a hipótese de que músicos comuniquem suas emoções aos ouvintes por meio do uso do mesmo código acústico utilizado em suas expressões vocais; este parâmetro tem sido averiguado por meio de estudos transculturais, que já comprovaram uma alta acurácia entre emoções expressas por músicos e as emoções percebidas por ouvintes, independentemente da cultura musical envolvida (Juslin, 2001; Johnstone; Scherer, 2000); (2) o aprendizado social, baseado em evidências de que a aprendizagem da comunicação das emoções ocorra por meio da fala, em um processo que começa 
com a relação do (futuro) músico com a sua mãe desde o pré-natal e que pode durar uma vida inteira; de fato, em um estudo feito por Papoušek (1996), por exemplo, foi comprovado que as mães expressam as suas desaprovações aos seus filhos por meio de contornos melódicos da fala relacionados ao staccato. Assim, segundo o Brunswikian lens model, as experiências de vida extramusicais do indivíduo são fundamentais para a aprendizagem da expressividade na performance musical (Woody, 2000).

Baseando-se nos parâmetros natural e de aprendizado social ilustrados pelo Brunswikian lens model (Juslin, 1997b), uma hipótese pode ser lançada acerca da influência do background musical de pianistas na expressão de suas emoções durante suas performances musicais: se os conteúdos intra e extramusicais aprendidos durante a vida toda do músico têm importância fundamental no processo de comunicação emocional, é possível supor que pianistas de formação erudita possam utilizar um código acústico (pistas musicais) diferenciado no processo de comunicação emocional em suas performances musicais em relação a pianistas de formação popular, na medida em que o ofício musical diário (e, portanto, o processo de "aculturação musical”) de cada um envolve o uso de estratégias cognitivas distintas. Segundo Parncutt e McPherson (2002), enquanto a excelência musical de pianistas eruditos é alcançada por meio de aspectos relacionados à leitura, à técnica digital e à rigidez no processo de interpretação musical, a excelência musical de pianistas populares é alcançada por meio de aspectos relacionados à prática da improvisação, da exploração do "ouvido musical”, da ausência de rigidez no processo de interpretação musical e da criatividade musical. Em outras palavras, pianistas eruditos são experts em algumas habilidades musicais enquanto que pianistas populares são experts em outras e, portanto, cada uma dessas expertises musicais pode levar a uma comunicação emocional diferente (Sloboda, 1985).

\section{Aplicação do Bruswikian Lens Model em Música Brasileira}


A maioria dos estudos que procuraram verificar a expressão das emoções musicais em ouvintes foram feitos a partir de estilos musicais relacionados à música erudita ocidental européia (Ilari, 2006). Até onde se sabe, nenhum estudo foi feito ainda neste campo de pesquisa com o emprego de música brasileira. No entanto, acredita-se ser possível a aplicação do Brunswikian Lens Mode/ no intuito de clarificar o processo de comunicação emocional entre o intérprete e o ouvinte brasileiros. Esta possibilidade de aplicação parece ser bastante viável devido a dois principais fatores: primeiro, pelo fato de que a influência branca (portuguesa, espanhola, francesa e italiana) foi a mais relevante na música brasileira: os portugueses, por exemplo, deram a sua contribuição por meio da fixação do nosso tonalismo harmônico, da quadratura estrófica, trazendo novos instrumentos musicais e literatura; os espanhóis, por meio de boleros, fandangos, seguidilhas, habaneras e zarzuelas; os italianos, por meio da divulgação da ópera no Brasil; os franceses, por meio dos cantos infantis e das operetas com textos em vernáculo; e ainda os austríacos e poloneses, respectivamente, por meio da valsa e da polca (Mariz, 2005). Segundo, pelo fato de que o Choro, estilo musical genuinamente brasileiro, já foi estudado exaustivamente do ponto de vista interpretativo e estrutural, ao piano.

O Choro é um estilo musical que começou a ser considerado um gênero com características definidas a partir da década de 1910, através do trabalho de Alfredo da Rocha Viana Filho, o Pixinguinha (Cazes, 1998). Os elementos estruturais característicos deste estilo musical são de natureza melódica, harmônica e rítmica. Tais elementos, entretanto, não são originais nem exclusivos do choro, e sua simples ocorrência não é suficiente para defini-lo como tal. Existe ainda outro aspecto importante, que é a maneira como ele deve ser executado, e que está relacionado com práticas interpretativas específicas, tais como uma sonoridade leve que permita manter a textura transparente, realização do ritmo de forma relaxada em relação ao pulso, uma articulação que enfatize a sincopa, e forma de frasear, geralmente sem exageros de dinâmica. Desta forma, a parte de piano solo de um choro funciona como uma redução orquestral, apresentando vários desafios para o 
compositor que deseja preservar tais elementos, e resultando em obras de dificuldade técnica considerável, muitas vezes em andamentos rápidos, que exigem do executante clareza de toque, independência entre as mãos e grande domínio no uso do pedal, entre outros (dos Santos, 2002).

No que concerne às pistas acústicas características do choro, após uma análise exaustiva de diversas peças deste estilo musical, Almeida (1999) organizou os seus elementos estruturais em quatro categorias: Melodia, Baixos, Harmonia e Ritmo. No que diz respeito à Melodia, as principais pistas acústicas encontradas foram: presença de apojaturas, bordaduras ornamentais e melódicas, cromatismo, ocorrência do arpejo maior descendente com sexta, frases longas, utilização da escala menor harmônica descendente sobre a dominante e valorização melódica do contratempo; no que concerne aos Baixos, as pistas encontradas foram linhas de baixo originadas a partir dos encadeamentos de acordes invertidos, que se desenvolvem até apresentar contornos melódicos, e que podem se estender até a região médio-aguda do instrumento (no caso, o violão) e apresentando diversos elementos característicos das melodias de choro, em que o baixo pode exercer as funções de condutor harmônico, (baixo) melódico e (baixo) pedal; no que concerne à Harmonia, encontrou-se o uso do acorde de Sexta Napolitana e o uso do acorde de dominante substituta (subV7), além do uso intensivo de acordes invertidos; e, finalmente, no que concerne ao ritmo, a ocorrência da sincopa, a alusão à sincopa e a presença de quiálteras foram as pistas acústicas encontradas.

Do ponto de vista pedagógico, a nossa experiência pessoal tem mostrado que este estilo musical está presente nas principais grades curriculares dos cursos de piano em escolas de música e conservatórios do Brasil, independente do background musical de seus praticantes; apesar disso, acredita-se que as estratégias cognitivas utilizadas por pianistas eruditos para a interpretação do choro sejam diferentes das estratégias cognitivas utilizadas por pianistas populares: enquanto no primeiro caso, as pistas para a interpretação são fornecidas pela partitura musical no sistema de onze linhas, envolvendo sinais de dinâmicas e outros conteúdos interpretativos, no segundo caso, o código 
empregado, em geral, acontece por meio de partitura simples, que envolve apenas clave de sol com cifragem harmônica, cabendo ao intérprete distribuir os acordes de maneira livre. De acordo com os princípios do Brunswikian lens model (Juslin, 1997b), é possível inferir que estas diferenças cognitivas de assimilação para a execução do choro ao piano possam desempenhar um papel importante na qualidade de seu processo interpretativo, no que diz respeito à comunicação emocional do estilo.

Assim, a influência marcante da música européia (tipo de música aplicável ao Brunswikian Lens Model) sobre a música brasileira, a existência de estudos envolvendo o código acústico empregado pelos choristas e o fácil acesso à execução deste estilo musical tanto por pianistas eruditos como populares no contexto social do Brasil, nos permitem lançar o desafio de se traçar um perfil emocional de um estilo musical genuinamente brasileiro, no intuito de clarificar aspectos envolvidos no processo de comunicação emocional em nossa própria cultura. Estes estudos já estão sendo desenvolvidos pelo Grupo de Pesquisa em Comunicação Emocional na Performance Musical, da Universidade Estadual de Campinas.

\section{Aplicações dos estudos sobre comunicação emocional na performance pianística em Educação Musical}

Apesar de existir uma forte ênfase relacionada à expressividade entre musicistas, um grande número de estudos sugerem que aspectos expressivos da performance musical têm sido negligenciado em Educação Musical. Especificamente, professores de piano tendem a gastar muito mais tempo, esforço e energia em aspectos técnicos do que em aspectos expressivos ou estéticos presentes na música (Tait, 1992; Persson, 1993). Como resultado, os estudantes podem vir a focar os aspectos expressivos demasiadamente tarde durante o desenvolvimento de seus sensos estéticos (Woody, 2000). De fato, na Europa e nos Estados Unidos, jovens pianistas vêm adquirindo um alto nível técnico sem, no entanto, se sentirem capazes de induzir uma experiência emocional agradável 
em seus ouvintes (Reimer, 1989). A mudança da ênfase "técnica” para a "expressiva" tende a levar a um crescimento real no uso de estratégias de habilidades expressivas empregadas no ensino das performances musicais dos estudantes. O ensino destas estratégias envolve, além de vocabulário próprio, formas de moldagem entre a cultura do compositor e a cultura do intérprete, e o gerenciamento de diversos procedimentos a serem empregados (Tait, 1992).

Quando um indivíduo está engajado em uma atividade musical, seja como instrumentista, ouvinte ou compositor, um grande número de processos psicológicos ocorrem em sua mente. A Cognição Musical é a ciência que estuda o regimento destes processos. Os estudos feitos nesta área têm mostrado que uma compreensão mais aprofundada sobre a mente do músico pode esclarecer questões centrais relacionadas a outras disciplinas do saber musical, como Interpretação instrumental, Percepção Musical, Harmonia, Apreciação Musical, Improvisação, Educação Musical, entre outras (Sloboda, 1985; Juslin; Sloboda, 2001; Ilari, 2006). Assim, a pesquisa sobre a comunicação emocional na performance musical pode contribuir para o desenvolvimento de estratégias de aprendizado que visem um aprimoramento da aplicação de aspectos expressivos na performance musical (Juslin; Persson, 2001).

\section{Referências}

ALMEIDA, A. Z. Verde e amarelo em preto e branco: as impressões do Choro no piano brasileiro. Campinas, Brasil. Dissertação de mestrado - Universidade Estadual de Campinas, Instituto de Artes, 1999.

$\mathrm{BACH}, \mathrm{C} . \mathrm{P} . \mathrm{E}$. Essay on the true art of playing keyboard instruments. London: Eulenburg Books, 1985 [1778].

BEHRENS, G. A.; GREEN, S. B. The ability to identify emotional content of solo improvisation performed vocally and on three different instruments. Psychology of Music, v. 21, p. 20-33, 1993.

BLUM, D. Casals and the art of interpretation. Berkeley: University of California Press, 1977.

BOYD, J.; GEORGE-WARREN, H. Musicians in tune: seventy-five contemporary musicians discuss the creative process. New York: Fireside, 1992.

CASES, H. Choro: do quintal ao Municipal. São Paulo. Editora 34, 1998. 
COOK, D. Music: a very short introduction. Oxford: Oxford University Press, 1998. . The language of music. London: Oxford University Press, 1959.

CLYNES, M. Sentics: the touch of emotions. New York: Anchor/Doubleday, 1977.

CROFTON, I.; FRASER, D. A dictionary of music quotation. London: Routledge, 1985.

DOS SANTOS, A. R. S. Análise e considerações sobre a execução dos choros para piano solo Canhôto e Manhosamente de Radamés Gnattali. Per Musi, v. 3, p. 5-16, 2002.

EKMAN, P. An argument for basic emotions. Cognition and emotion, v. 6, p. 169-200, 1992.

GABRIELSON, A. ; JUSLIN, P. N. Emotional expression in music performance: between the performer's intention and the listener's experience. Psychology of Music, v. 24, p. 68-91, 1996.

HEVNER, K. Experimental studies of the elements of expression in music. American Journal of Psychology, v. 48, p. 246-268, 1936.

ILARI, B. S. Em busca da mente musical. Curitiba. Editora UFPR, 2006.

JOHNSTON, T.; SCHERER, K. R. Vocal communication of emotion. In: LEWIS, M.; HAVILAND-JONES, J. M. (Eds.). Handbook of emotions. 2.ed. New York: Guilford, 2000. p. 220-235.

JUSLIN, P. N. Communicating emotion in music performance: a review and a theoretical framework. In: JUSLIN, P. N.; SLOBODA, J. A. (Eds.). Music and emotion: theory and research. New York: Oxford University Press, 2001. p. 309-337.

. Cue utilization in communication of emotion in music performance: relating performance to perception. Journal of Experimental Psychology: Human Perception and Performance, v. 26, p. 1797-1813, 2000.

48 . Emotional communication in music performance: a functionalist perspective and some data. Music Perception, v. 14, p. 383-418, 1997.

JUSLIN, P. N.; MADISON, G. The rolling of time patterns in recognition of emotional expression from music performance. Music Perception, v. 17, p. 197-221, 1999.

JUSLIN, P. N.; PERSSON, R. S. Emotional communication. In: PARNCUTT, R.; MCPHERSON, G. E. (Eds.). The science and psychology of music performance: strategies for teaching and learning. New York: Oxford University Press, 2002. p. 219-236.

JUSLIN, P. N.; SLOBODA, J. A. Music and emotion: theory and research. New York: Oxford University Press, 2001.

KOTLYAR, G. M.; MOROZOV, V. P. Acoustic correlates of the emotional content of vocalized speech. Soviet Physiscs: Accoustics, v. 22, p. 370-376, 1976.

LANGUER, S. K. Philosophy in a new key. Cambridge, MA: Harvard University Press, 1942.

MARIZ, V. História da Música no Brasil. Rio de Janeiro: Nova Fronteira, 2005.

MENUHIN, Y. Unfinished journey. London: Methuen, 1996.

METHENSON, J. Der vollkommene Coppellmeister. Bärenreiter: Basel, 1739/1954.

MEYER, L. B. Emotion and meaning in music. Chicago: University of Chicago Press, 1956. 
OATLEY, K.; JUNKINS, J. M. Understanding emotions. Oxford: Blackwell, 1996.

PAPOUŠEK, M. Intuitive parenting: a hidden source of musical stimulation in infancy. In: DELIEGE, I.; SLOBODA, J. A. (Eds.). Musical beginnings: origins and development of musical competence. Oxford: Oxford University Press, 1996. p. 88-112.

PARNCUTT, R.; MCPHERSON, G. E. The Science and Psychology of Music Performance. New York: Oxford University Press, 2002.

PERSSON, R. S. The subjectivity of music performance: a music-psychological real world enquiry into determinants and education of musical reality. Doctoral dissertation. Huddersfield University, UK, 1993.

RAMOS, D.; BUENO, J. L. O.; BIGAND, E. Manipulating Greek musical modes and tempo results in continuous changes in perceived musical emotion along arousal and valence dimensions. Brazilian Journal of Medical and Psychological Research, no prelo.

RAPOPORT, E. Emotional expression code in opera and lied singing. Journal of New Music Research, v. 25, p. 109-149, 1996.

REIMER, B. A philosophy of music education. Englewoods Cliffs: Prentice-Hall, 1989.

RUSSEL, J. A. A circumplex model of affect. Journal of Perssonality and Social Psychology, v. 39, p. 1161-1178, 1980.

SCHUMAKER, M. Crossroads: the life and music of Eric Clapton. New York: Hyperion, 1995.

SLOBOdA, J. A. A mente musical: a Psicologia Cognitiva da Música. Ed.; Trad.: B. S. Ilari. Curitiba: Editora UFPR, 2008.

SLOBODA, J. A. The acquisition of musical performance expertise: deconstructing the "talent" account of individual differences in musical expressivity. In: ERISCSSON, K. A. (Ed.). The road to excellence. Mahwah: Erlbaum, 1996. p. 107-126.

SUNDBERG, J.; IWARSSON, J.; HAGEGÅRD, H. A singer's expression of emotions in sung performance. In: FUJIMURA, O.; HIRANO, M. (Eds.). Vocal fold physiology: voice quality control. San Diego: Singular Press, 1995. p. 217-229.

TAIT, M. Teaching strategies and styles. In: COLWELL, R. (Ed.). Handbook of research on music teaching and learning. New York: Schirmer, 1992. p. 525-534.

WOODY, R. H. Learning expressivity in music performance: an exploratory study. Research Studies in Music Education, v. 14, p. 14-23, 2000.

Danilo Ramos: danramosnilo@gmail.com Rafael do Santos: rdsantos@unicamp.br Artigo recebido e aprovado em 06/10/2010 
